\title{
What Teachers Do: Facilitating the Writing Process with the Feedback from EssayCritic and Collaborating Peers
}

\section{Irina Engeness}

Department of Education, University of Oslo, Norway

Full correspondence address:

Irina Engeness

Department of Education, Faculty of Educational Sciences

University of Oslo

P.O Box 1099 Blindern

0317 Oslo

e-mail: Irina.engeness@iped.uio.no

Short biographical note:

Irina Engeness is a PhD Candidate at the Department of Education, University of Oslo. She has written about and her research interests include:

- Technology and English Language Learning: The role of digital and other mediational tools in English language learning, educational technology; computer-supported collaborative learning (CSCL);

- Assessment for Learning: development of writing skills in English, writing process, formative assessment, feedback

- Learning and Development: Cultural-historical theory, agency of students and teachers, learning to learn approach

\section{Acknowledgements}

This study was funded by the Faculty of Educational Sciences, University of Oslo, Norway. The collection of the data was conducted in the frame of the project Ark\&App funded by the Ministry of Education of Norway. I thank Professor Anders Mørch and Professor Anne Edwards for their comments on the early drafts of this study. 


\title{
What Teachers Do: Facilitating the Writing Process with the Feedback from EssayCritic and Collaborating Peers
}

\begin{abstract}
The study provides an insight into how technology may affect teachers' facilitating of the writing process which was examined and compared when Norwegian Upper Secondary School students wrote essays about English as a Global Language through multiple drafts with feedback received from the computer-based essay critiquing system (EssayCritic) (target class) and from collaborating peers (comparison class). Quantitative and qualitative analyses of the teachers' assistance draw on Galperin's conceptualisation of learning. Findings reveal patterns in the teachers' guidance in both conditions and outline the differences arising from the use of EssayCritic: by interacting with EssayCritic the teacher assisted the learners in completing the specific task, although little attention was paid to the development of their assessment for learning (AfL) skills. However, in the comparison class the teacher paid attention to the development of students' AfL skills by emphasising the general approach to the analysis and the essential requirements of the essays. The study, therefore, raises questions about the need for practitioners' awareness of whether the technology supports the development of, for example, AfL skills required in English writing classes.
\end{abstract}

Keywords: Teachers' facilitating of the writing process; EssayCritic; Galperin; Cultural Historical Theory

\subsection{Introduction}

In common with other countries, feedback and assessment for learning (AfL) have been encouraged in Norwegian schools and AfL has been defined as a classroom practice that involves dialogue and feedback loops between teachers and peers during subject specific problem solving (Gamlem \& Munthe, 2014). The integration of AfL in classrooms imposes a division of labour between teachers and students and implies the expectation for students to take increased responsibility for their own learning (Crossouard, 2009; Brookhart et al., 2010).

While digital technologies open up opportunities for enhancing the development of students' writing skills in English (Lee, 2007; Mørch et al., 2005), knowing how to facilitate students' learning with technology and promote AfL skills is a key challenge for teachers. Although several studies have explored the types of feedback teachers give on students' writing (Yang, et al., 2006; Zhao, 2010), very few studies have examined how teachers facilitate learners' capacity for process-oriented writing (Thompson, 2013). By taking a cultural-historical perspective on teaching and learning (Edwards, 2015; Galperin, 1969; 
Vygotsky, 1981) this study aims to fill the gap. The study was undertaken in an Upper Secondary School in Norway, involving students aged 16-17 who wrote essays on the topic English as a Global Language. Teachers' facilitating of students writing under two conditions of mediation has been examined: the students in the target class received feedback from the computer-based essay critiquing system (EssayCritic) and the students in the comparison class gave feedback to each other using available (non-computerised) support tools. Galperin's conceptualisation of learning (Haenen, 2001; Rambusch, 2006) is introduced to provide explanation for the different conditions of mediation and is used as a lens to examine teachers' facilitating of students' learning in similar phases of the writing process.

\subsection{Facilitating the writing process}

The ways the teachers structure the writing classroom and the type of feedback they give determine how their students approach the writing process, view feedback and make revisions in their writing (Lockhart \& Ng, 1995; Paulus, 1999). However, previous research has mainly focused on the types of feedback teachers give on students' writing, showing that specific, ideas-based, meaning-level feedback in the context of multiple-drafts can be effective in promoting student revision (Hyland, 1990).

One type of feedback, written corrective feedback (CF), otherwise known as error correction or grammar correction (Hartwell, 1985; Truscott, 1996), has been a controversial topic among practitioners working with English as a second language (ESL) learners in writing classes. It was argued that ESL teachers should deemphasise grammar instruction and correction allowing the students to discover their ideas through a recursive process of drafting, and receiving feedback (Hartwell, 1985; Truscott, 1996). Others, however, pointed out that such benign view of CF issues linguistic gaps that most ESL writers bring into advanced writing situations (Johns, 1995; Reid, 1994). Recent studies provide evidence that written CF, under the right conditions, can help ESL students improve the accuracy of their writing and facilitate the development of their linguistic skills (Bitchener \& Knoch, 2008; Ellis et al., 2008; Sheen 2007). However, when aiming to improve the quality of students' written work and develop learners as writers, a variety of teaching approaches beyond CF, such as explicit instruction, strategy training and peer- and self-editing activities can be used (Ferris, 2010; 2006).

Research (Black \& Wiliam, 2009) has also conceptualised feedback as a form of formative assessment consisting of five key strategies: clarifying and sharing learning 
intentions and criteria for success; engineering effective classroom discussions and learning tasks that elicit evidence of student understanding; providing feedback that moves learners forward; activating students as instructional resources for one another and as owners of their own learning. According to Hattie and Timperley (2007) effective feedback must answer three major questions: Where am I going? How am I going? and Where to next? These questions correspond to the notions of feed up, feedback and feed forward (Hattie \& Timperley, 2007). Four levels of feedback have been identified: feedback about the task, about the processing of the task, about self-regulation and about the self as a person. It has been argued that feedback on how to complete a task is the most effective, whereas feedback related to praise, reward and punishment is the least effective (Hattie \& Timperley, 2007).

Despite the considerable body of research on the types of feedback, surprisingly few studies examined teachers' facilitating of the writing process over time. It has been suggested that in the writing process the teacher should remain quiet, listen and respond, be the reader and the recipient (Murray, 1972). On the other hand, Thompson (2013) argues that attention needs to be paid to the construction of student's zone of proximal development (ZPD) through collaborative activity, for it is negotiation and active interventions by a teacher within this zone that lead to development of students as writers. Several studies have attempted to pinpoint the various forms of mediation that affect students' progress within a ZPD (Del Rio \& Alvarez, 2007; Smagorinsky, 2007; Thompson, 2012): among the methods are direct instruction from a teacher or more capable peer and feedback that offers guidance on performance. In an attempt to emphasise the importance of an educational dialogue in which feedback is central, Smith and colleagues introduced the concept of responsive pedagogy comprising recursive dialogue between the learner's internal feedback and external feedback provided by significant others (Smith et al., 2016). An essential part of responsive pedagogy is an explicit intention of the teacher to make learners believe in their own competence and the ability to complete tasks to enhance students' capacity to learn. However, when technology is used, teachers' instructions can be downplayed and peer feedback amplified as classrooms are often regarded as student-centred (Collins, 2001; Hancock \& Betts, 1994). Consequently, the teacher's role has shifted from being the source of information to being a facilitator of students' learning (Chin \& Hortin, 1993).

This shift in the position of the teacher has also been influenced by the capacity of technology to give feedback to students on their writing. Previous research on computer-based feedback systems includes automated essays scoring (AES) systems which assign scores to essays written for educational purposes. The score is dynamically determined by machine 
learning and statistical techniques based on a set of training examples, which typically range from 50 to several hundred, dependent on the desired precision of the automated feedback (Dikli, 2006). AES applications have been reported for low-stakes testing situations (classrooms) and high-stakes testing (national tests). On the one hand, proponents argue for their success in terms of how well they compare with the accuracy and reliability of human evaluation (Chung \& O'Neil Jr, 1997; Sireci \& Rizavi, 2000). On the other hand, critics have pointed out that AES systems can often be fooled by intentionally gibberish essays by giving them high scores (Kukich, 2000; Winerip, 2012).

Early studies of EssayCritic (Mørch et al., 2005) showed its usefulness as a tool facilitating writing in English and supplementing teachers' feedback. However, a study in Hong Kong found no significant difference between the grades achieved by students who used EssayCritic and those who revised their texts themselves (Lee, et al., 2009). A later study of the same system (Lee, et al., 2013) compared two conditions: one group that received feedback from EssayCritic and from the teacher, and another group that received feedback from the teacher only. In this study, the essays of the group that received two types of feedback were richer in content than the essays of the other group.

Although the observations outlined here indicate a shift in how teachers may be able to facilitate the writing process with and without technology, studies tend to lack detail on what teachers actually do when interacting with English as a second/foreign language (ESL/EFL) (Brevik, 2017; Rindal, 2010; Rindal \& Piercy, 2013) students in these new conditions in writing classes.

\subsection{Cultural-historical perspective on facilitating of students' learning to write}

A cultural-historical perspective has been chosen to examine teachers' facilitating of the writing process as a way of developing learners as writers. Vygotsky made a clear distinction between learning and development (Vygotsky, 1981), where the latter requires changes in the psychological functions of the learner (Chaiklin, 2003). According to Vygotsky, the acquisition of cultural tools, such as language, signs, and concepts, constitutes the main content of the child's mental development. Hence, Vygotsky put particular emphasis on the role of instruction as the major provider of those tools. In Vygotsky's view, the quality of instruction is crucial in terms of the effects it produces on development (Stetsenko \& Arievitch, 2002). 
However, Vygotsky himself did not specify how the particular content of instruction is related to development, and in particular, how specific qualities of the tools acquired by the child affect development. A cultural-historical scholar Galperin has greatly extended Vygotsky's arguments about the leading role of instruction in the child's development by specifying the kind of instruction that can play such a role (Stetsenko \& Arievitch, 2002).

Specifically, Galperin's research strategy was to analyse how new mental processes emerge in the context of meaningful, goal-oriented activities of teaching and learning (Haenen, 2001). Galperin explained that the transformation of the socially meaningful external activity into a new psychological function happens through a series of six dialectically evolving phases: (1) motivation, (2) orientation, (3) materialised action, (4) communicated thinking, (5) dialogical thinking, and (6) acting mentally (Haenen, 2001; Rambusch, 2006).

In the initial motivational phase, a learner's attitude and relation to the learning outcomes that have to be achieved is formed. In the second orientation phase, Galperin identified three types of orientation: (a) incomplete, where mediational means and the essential features of the studied concept are identified by learners through multiple trial and errors; (b) complete, where learners are informed about all the mediational means and the essential features of the concept necessary to solve a particular problem; (c) complete, but being constructed by learners following a general approach of identifying the essential features of the studied concept. In our case this implies the type of assistance provided to enhance students' analysis of essays from the perspective of the essential requirement of a variety of subthemes. In the third phase of a materialised action learners interact with material or materialised objects, and over time become less dependent on the material support they give and more aware of the meanings they carry. Speech becomes the main guiding tool in the fourth phase of communicated thinking. The fifth phase, dialogical thinking, establishes a dialogue of a learner with him or herself so that the action is being transformed mentally. In the final phase of acting mentally, an action has become a pure mental act with the focus on the outcome of the action. The action is performed by means of mental images and meanings that help a learner to deal with similar or differing situations on the basis of previous experience.

These six phases of the learning activity lie at the core of the discussions about teacher actions that follow and they can inform both teachers and researchers about the complexity of the processes involved in a learner's move from, for example, orientation to the potential of advice for how to write, to the ability to act as a writer. The quality and appropriateness of the 
teachers' instructions during the phases that lead to that ability would seem to be crucial. From this perspective, the following research questions are addressed in this study:

RQ1: How do teachers facilitate students' writing process with the feedback from EssayCritic and collaborating peers?

RQ2: How does EssayCritic affect teachers' facilitating of students' writing?

\subsection{Methods}

\subsection{Participants and setting}

Data collection was conducted in an Upper Secondary School in Norway that has taken AfL as a focal area of practice development. 125 students (aged 16-17) from five classes wrote an essay on the topic English as a Global Language during an English lesson based on the information studied previously in class and the content of a chapter in the textbook Passage (Burgess \& Sørhus 2009). The text of the assignment was created in collaboration between five teachers and two researchers: "Write an essay on the topic of English as a Global Language: Explore how English was spread around the globe, and present the most important reasons for this development" (300-400 words).

In the first round 125 students wrote the first draft of the essay using a laptop as a writing tool and an assessment rubric used by the school which contained the essential requirement of a variety of subthemes and the list of the subthemes to include. An independent teacher marked all the essays according to the assessment rubric and 50 essays from three classes awarded 4, 5 and 6 (on the scale 1-6) were selected to code for the subthemes of the topic English as a Global Language and to train EssayCritic as a resource for the students.

The remaining two classes (48 students) were assigned as the target and comparison class. Both classes were divided in groups of four students by the teachers. The students of the target class uploaded the first draft to EssayCritic and after they had discussed the feedback received from the system with their peers, they produced the second draft. The students of the comparison class read each other's essays and gave advice on how to create the second draft. All students repeated the process of receiving feedback and revising their essays one more time, which resulted in the production of the third draft handed in to the teachers for final evaluation. The sequence of the activities in the writing process is presented in Table 1.

Table 1. The sequence of the activities in the writing process in the target and comparison classes

\begin{tabular}{llll}
\hline Date & Duration & Learning resources & Technology used
\end{tabular}




\begin{tabular}{|c|c|c|c|c|c|}
\hline \multirow{3}{*}{ 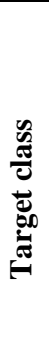 } & 28.10 . & $90 \mathrm{~min}$ & Writing of essay, version 1 & $\begin{array}{l}\text { Assessment rubric } \\
\text { List of subthemes }\end{array}$ & $\begin{array}{l}\text { Laptop as a writing } \\
\text { tool }\end{array}$ \\
\hline & \multirow[t]{2}{*}{05.11 . } & $90 \mathrm{~min}$ & $\begin{array}{l}\text { Discussion of feedback from } \\
\text { EssayCritic on version } 1 \\
\text { Writing of essay, version } 2\end{array}$ & $\begin{array}{l}\text { Assessment rubric } \\
\text { List of subthemes }\end{array}$ & $\begin{array}{l}\text { Laptop } \\
\text { EssayCritic }\end{array}$ \\
\hline & & $90 \mathrm{~min}$ & $\begin{array}{l}\text { Discussion of feedback from } \\
\text { EssayCritic on version } 2 \\
\text { Writing of essay, version } 3\end{array}$ & $\begin{array}{l}\text { Assessment rubric } \\
\text { List of subthemes }\end{array}$ & $\begin{array}{l}\text { Laptop } \\
\text { EssayCritic }\end{array}$ \\
\hline \multirow{3}{*}{ 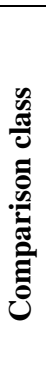 } & 28.10 . & $90 \mathrm{~min}$ & Writing of essay version 1 & $\begin{array}{l}\text { Assessment rubric } \\
\text { List of subthemes }\end{array}$ & $\begin{array}{l}\text { Laptop as a writing } \\
\text { tool }\end{array}$ \\
\hline & \multirow[t]{2}{*}{06.11.} & $90 \mathrm{~min}$ & $\begin{array}{l}\text { Discussion of peer feedback on } \\
\text { version } 1 \\
\text { Writing of essay, version } 2\end{array}$ & $\begin{array}{l}\text { Assessment rubric } \\
\text { List of subthemes }\end{array}$ & $\begin{array}{l}\text { Laptop as a writing } \\
\text { tool }\end{array}$ \\
\hline & & $90 \mathrm{~min}$ & $\begin{array}{l}\text { Discussion of peer feedback on } \\
\text { version } 2 \\
\text { Writing of essay, version } 3\end{array}$ & $\begin{array}{l}\text { Assessment rubric } \\
\text { List of subthemes }\end{array}$ & $\begin{array}{l}\text { Laptop as a writing } \\
\text { tool }\end{array}$ \\
\hline
\end{tabular}

During the intervention the teachers (both females in early 50s with Master's Degrees and more than 20 years of teaching experience) circulated among the groups and addressed various questions. The researchers did not interfere in the group work.

\subsection{EssayCritic System}

EssayCritic is a web application that analyses uploaded essays with the help of a Decision Tree machine-learning algorithm (Quinlan, 1986), synonyms from dictionaries and a lexical database for English WordNet (Fellbaum, 1998) and generates feedback based on the content of the essays. Before using the system, a concept tree representing the essay topic was created. The teachers identified a set of desired subthemes for the topic and the researchers decomposed each subtheme into simpler concepts, represented by a few phrases or expressions taken from the students' essays that were selected to train the system, together with the synonyms from the dictionaries and the WordNet lexical database. In doing this, a "model" was created and the process of training the system took approximately one month.

Once a new essay was written and uploaded by a student, the system computed a score for the uploaded essay's similarity with the model for each of the subthemes. If this score was below a threshold value, "critique" was given for missing the corresponding subtheme, and if above the threshold, the subtheme was considered to be a part of the essay, and was highlighted in the essay. Figure 1 shows the screen pictures of EssayCritic. 

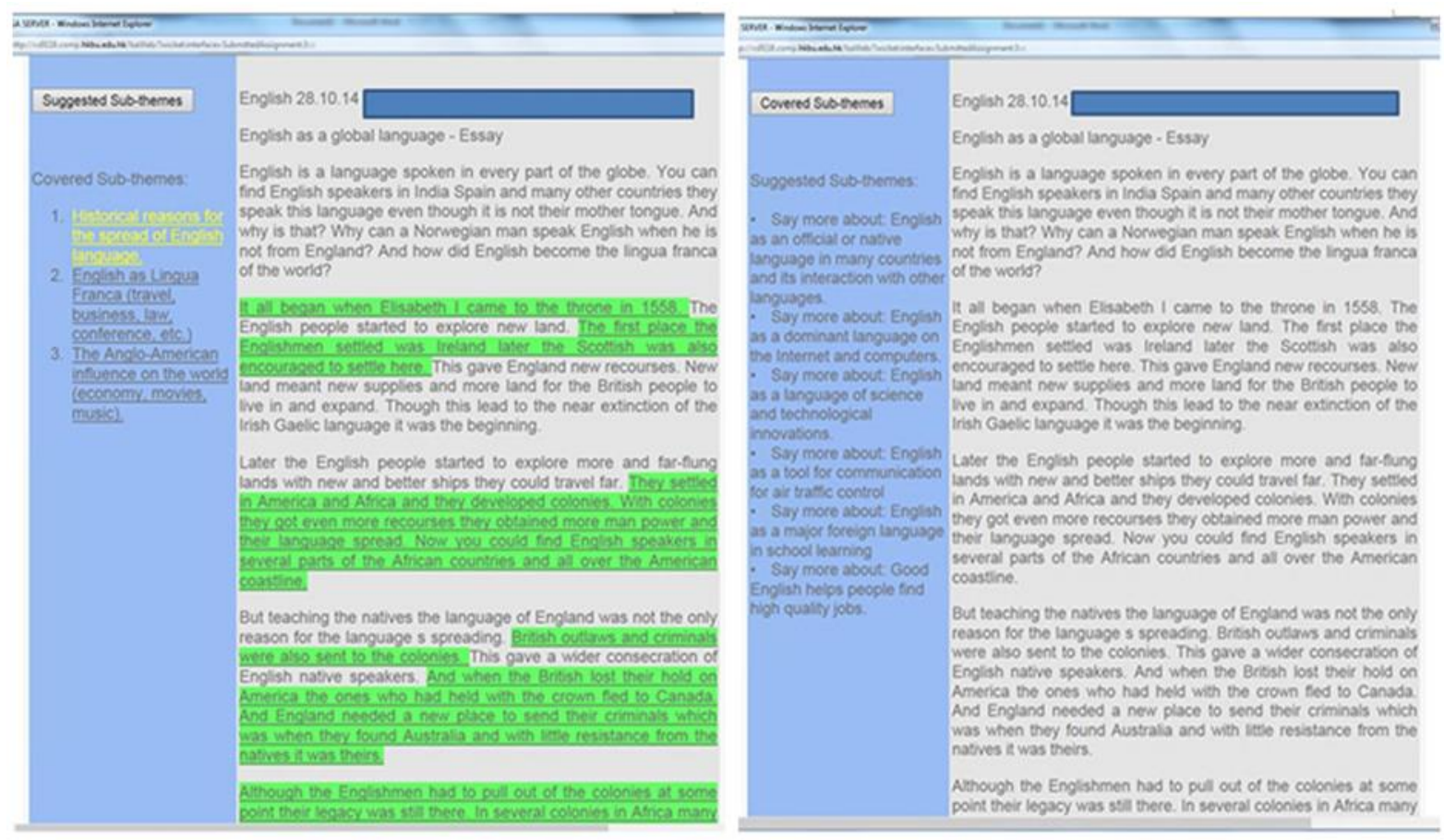

Figure 1. The user interface of EssayCritic: covered subthemes (left) and suggested subthemes (right)

\subsection{Data and analysis}

Three groups of four students who volunteered to participate in the project in both classes were video recorded. Another camera followed the teachers. Nine hours of video recordings were transcribed according to the Jeffersonian transcription notations (Appendix A) (Atkinson \& Heritage, 1999). Field notes taken during class observations were used to contextualise the data (Derry et al., 2010).

To examine teachers' facilitating of students' learning in the writing process and give credibility to these analyses, mixed methods (Creswell, 2012) were applied to analyse the data by providing quantitative and qualitative evidence about processes of tool use. The number of the teachers' interventions in the phases of orientation, communicated and dialogical thinking of the writing process in the target and comparison classes were calculated by the research team during classroom observations. The Mann-Whitney test (Mann \& Whitney, 1947; Field, 2013) was used to calculate statistical difference between the number of teachers' interventions in both classes in similar phases of the writing process.

To examine the nature of teachers' facilitating of students' writing, teacher-student interactions were analysed qualitatively. Initially, a substantial number of episodes (22), which represent teacher-student interactions in the observed groups were analysed. Thereafter, a so-called 'story' (Derry et al., 2010) emerged through the analysed extracts, 
which determined the final selection of the extracts chosen to represent patterns in teacherstudent interactions in similar phases (Rambusch, 2006) of the writing process. Six interaction extracts are presented in this study: three extracts from a group in the target class (happened in the phases of orientation, communicated and dialogical thinking) and three extracts from a group in the comparison class (happened in similar phases). The students communicated in English and the presented extracts have not been modified. The analytical procedure was inspired by interaction analysis, where interactions between interlocutors were analysed sequentially (Jordan \& Henderson, 1995). The primary unit of analysis was sequences and turns rather than isolated utterances (Linell, 2009). The description of the setting precedes each interaction sequence (Geertz, 1973), to locate the chosen extracts in the flow of classroom events. Once the interaction analysis was completed, the interactions were examined through the analytic lens offered by Galperin's types of orientation to explain the conditions of mediation in both classes.

\subsection{Findings}

\subsection{Analysis of teachers' interventions}

The analysis of teachers' facilitating of the writing process in the target and comparison classes starts by examining the number of teachers' interventions in similar phases (Haenen, 2001; Rambusch, 2006) in the writing process (Table 2).

Table 2. Average number of teachers' interventions in the target and comparison classes and the observed groups

\begin{tabular}{|c|c|c|c|c|c|}
\hline & $\begin{array}{l}\text { Orientation } \\
\text { phase }\end{array}$ & $\begin{array}{l}\text { Communicated } \\
\text { thinking }\end{array}$ & $\begin{array}{l}\text { Dialogical } \\
\text { thinking }\end{array}$ & $\begin{array}{l}\text { One-way } \\
\text { test }\end{array}$ & ANOVA \\
\hline Target class & $\begin{array}{l}1.67 \\
M=1.67 \\
S D=0.58\end{array}$ & $\begin{array}{l}3.33 \\
\mathrm{M}=3.33 \\
\mathrm{SD}=0.58\end{array}$ & $\begin{array}{l}1.00 \\
\mathrm{M}=1.00 \\
\mathrm{SD}=0.00\end{array}$ & $\mathrm{p}=.002$ & \\
\hline $\begin{array}{l}\text { Observed target } \\
\text { group }\end{array}$ & 1.00 & 3.00 & 1.00 & & \\
\hline Comparison class & $\begin{array}{l}5.00 \\
M=5.00 \\
S D=1.00\end{array}$ & $\begin{array}{l}6.33 \\
M=6.33 \\
S D=0.58\end{array}$ & $\begin{array}{l}1.67 \\
M=1.67 \\
S D=0.58\end{array}$ & $\mathrm{p}=.001$ & \\
\hline $\begin{array}{l}\text { Observed } \\
\text { comparison group }\end{array}$ & 6.00 & 7.00 & 2.00 & & \\
\hline
\end{tabular}




\begin{tabular}{llll}
\hline Independent t-test $\mathrm{p}=.007$ & $\mathrm{p}=.003$ & $\mathrm{p}=.116$ \\
\hline
\end{tabular}

The data points out the differences in the teachers' facilitating of students' learning between the phases of the writing process and the classes. The number of teachers' interventions in different phases of the writing process in the target and comparison classes differ. In both classes, the teachers intervened more times in the phases of orientation and communicated thinking than in dialogical thinking. The Mann-Whitney test (Mann \& Whitney, 1947; Field, 2013) reflects significant statistical difference ${ }^{1}$ between the number of teachers' interventions in the phases of orientation and communicated thinking: the teacher in the comparison class provided significantly more assistance than the teacher in the target class. In the phase of dialogical thinking, however, there is no statistical difference between the number of teachers' interventions in the target and comparison classes. These findings indicate the need to examine the nature of teachers' interventions in both classes qualitatively.

\subsection{Analysis of the teacher-student interactions in the target class}

Time: 09:24

In the extract $1 \mathrm{a}$ in Table 3 the learners are at the beginning of the writing process. Four students are sitting around the table with their laptops open. They have just uploaded their first drafts to EssayCritic and received feedback from the system: the learners are in the orientation phase. The teacher approaches the group and asks the following:

\section{Table 3. Extract 1a}

\begin{tabular}{lll}
\hline 1. & Teacher: & Do you have any questions? \\
2. & Carol: & I have found my essay, but I don't know how many words I have. \\
3. & Teacher: & Oh, you are looking for words. \\
4. Carol: & Yes. \\
5. Teacher: & So, who wants to start here? \\
6. Jane: & How would you like us to do that? Do we just say what the comments were? \\
7. Teacher: & Yes, you can turn your laptop around, so everyone can see your essay. Tell them what \\
& & feedback you have got and then you can discuss. After that you can write. \\
8. & Kate: & ((turns her laptop screen to the group $))$ I think these are the comments ((points at the \\
& & Yes $))$
\end{tabular}

\footnotetext{
${ }^{1} \mathrm{p}>.05$ indicates no significant statistical difference (Field, 2013)
} 
In extract $1 \mathrm{a}$, in the orientation phase, the teacher takes the role of setting up the writing process (lines 5,7 ). She clarifies the details of the process, orients the students and encourages students' interactions with EssayCritic as a mediating tool (line 7). The teacher performs an orienting role, and this function is of particular importance in the orientation phase as it creates a basis for establishment and presence of the support tool - EssayCritic to assist students' learning.

Time: 09:53

The events presented in extract $1 \mathrm{~b}$ in Table 4 chronologically follow the events in extract 1a. The students have just discussed the feedback given to Kate and it is Jane's turn to share her feedback (Say more about English as an official language in many countries): the learners are in the phase of communicated thinking. The teacher approaches the group and Jane asks the following:

\section{Table 4. Extract 1b}

\begin{tabular}{|c|c|c|}
\hline 1. & Jane: & $\begin{array}{l}\text { Bilingual - is it when you have two official languages, like Canada? Is India a bilingual } \\
\text { country? }\end{array}$ \\
\hline 2. & Teacher: & Yes, I can say so. \\
\hline 3. & Jane: & Is English an official language, but do they have other native languages? \\
\hline 4. & Teacher: & Yes, they have other native languages as well. \\
\hline 5. & Jane: & $\begin{array}{l}\text { Does that make those official languages too? Because I think that English is their official } \\
\text { language and they don't have two official languages. They can't be a bilingual country. }\end{array}$ \\
\hline 6. & Teacher: & No \\
\hline 7. & Kate: & Is Canada bilingual, because they have English and French as official languages? \\
\hline 8. & Teacher: & Yes \\
\hline 9. & Carol: & I have read that India and Singapore are bilingual countries. \\
\hline 10. & Teacher: & What's another official language in India? No, you've said Singapore. \\
\hline 11. & Carol: & I am not sure. But I know one of them is English. \\
\hline 12. & Teacher: & Yes it is. \\
\hline 13. & Carol: & $\begin{array}{l}\text { But the second language, I am not so sure- I wrote that Canada is a bilingual country, but } \\
\text { I think it's wrong when I wrote India and Singapore. Is it right or not? }\end{array}$ \\
\hline 14. & Teacher: & ((Looks at Kate's screen $))$ Did you get anything wrong on India, Singapore and Canada? \\
\hline 15. & Jane: & $\begin{array}{l}\text { I don't think it checks whether it's wrong or not, but if you mention any of the } \\
\text { subthemes. }\end{array}$ \\
\hline 16. & Teacher: & I think you can write about Canada. \\
\hline 17. & Jane: & So, you can switch India and Singapore with Canada. And then we are OK, I guess. \\
\hline
\end{tabular}


18. Carol: Ok, thank you ((Teacher leaves the group))

The students are trying to make sense of the concept "bilingual country" (lines 1, 3, 5, 7 and 9) and the teacher helps the students to structure their knowledge. In particular, the teacher helps to identify the main criterion of a bilingual country: two official languages (line 10). However, the teacher seems to be unsure herself and she seeks confirmation from EssayCritic by checking the feedback the system gave to Kate (line 14). Once she has been informed that the program gives another type of feedback, she suggests the learners to focus on Canada (line 16).

The teacher demonstrates dependency on the type of feedback EssayCritic provides and students' own reflections on whether other countries can be labelled as bilingual appear to be downplayed.

In fact, Jane included the following text in her final draft:

"When the British lost their hold on America, the ones who had held with the crown fled to Canada, this gave the country a second language aside from French. Canada is today an example of a bilingual country."

Carol wrote the following passage:

"In some countries in the world, they have two official languages, and that's what we call a bi-lingual. Canada is a great example of that because French is widely spoken and it's their $2^{\text {nd }}$ language after English."

This indicates that the ideas the students made sense of in collaboration with the teacher and EssayCritic were incorporated in their essays or, in Galperin's terms, the knowledge coconstructed in communicated thinking was transferred to the phase of dialogical thinking.

Time: 11:16

The events in extract 1c in Table 5 chronologically follow the events in extract $1 \mathrm{~b}$. The students have now produced their second drafts, uploaded to EssayCritic and received feedback from the program. Working on their final drafts, the learners are moving from the phase of communicated to dialogical thinking. The teacher approaches the group when the learners are in the middle of discussing the feedback Carol received from EssayCritic on her second draft. 
Table 5. Extract 1c

\begin{tabular}{lll}
\hline 1. Teacher: & Have you got any questions on the feedback on your second draft? \\
2. Carol: & I have covered seven subthemes and I need two more. \\
3. Jane: & Same here. I covered three when I submitted my first draft and now I have \\
& & covered seven. \\
4. Teacher: & Oh, that's very well. \\
5. Jane: & But I think the structure of my text is bad. \\
6. Teacher: & Have a look at the structure as well.
\end{tabular}

The learners report on the feedback about the covered subthemes they received from EssayCritic (lines 2,3) to the teacher who confirms that the students are on the right track in meeting the requirements of the assignment (lines 4, 6). In doing so, the teacher might have initiated the learners' reflections about the essential requirements of the essays. However, similarly to extract $1 \mathrm{~b}$, the teacher demonstrates her reliance on the feedback from EssayCritic, which might have been at the expense of learners' understandings of how to go about the analysis of the content of their essays.

\subsection{Analysis of the teacher-student interactions in the comparison class}

Time: 09:36

The students of the comparison class have received the first marked drafts of their essays from the teacher. In extract $2 \mathrm{a}$ in Table 6 four students are sitting around the table; Josh and Mike have just read each others' essays and they are about to start giving feedback to each other: the learners are in the orientation phase. We start when the teacher approaches the group.

\section{Table 6. Extract 2a}

\begin{tabular}{lll}
\hline 1. Teacher: & If you have any questions, I will go around and help you. Remember to focus on the \\
& content. Since the text we have read is about history, many of you thought that history \\
& was the most important part. There are many other aspects, like media and so on. \\
& & Does the essay still have to be between 300 and 400 words? \\
2. Josh: & Yes. If you have too much on history, you can shorten that. \\
3. Teacher: & What do you mean by "clumsy"? \\
4. Mike: & I do understand what you are trying to say, but you should reformulate it. \\
5. Teacher: & Mou can, actually, write more than 400 words and include more information and topics. \\
6. & Meacher: & You
\end{tabular}


The teacher takes the role of setting up the writing process. She reminds the students about the essential requirements of their essays (the content) and how to meet them (line 1). The learners clarify the details of the process: they seek confirmation on the length of the essay (line 2) and ask for clarification on the teacher's comments (line 4). The teacher, in turn, brings students' attention to the length and the variety of subthemes as an essential feature of their second drafts (line 7) and in doing so, learners' reflections about the main requirements of the essay and how to meet them might have been encouraged.

Time: $10: 23$

The events in extract $2 \mathrm{~b}$ in Table 7 chronologically follow the events in $2 \mathrm{a}$. Josh and Mike are in the middle of giving feedback on how to improve their second drafts: they are in the phase of communicated thinking. The two boys have already started making changes in their texts when the teacher asks Mike:

\section{Table 7. Extract 2b}

\begin{tabular}{lll}
\hline 1. & Teacher: & Do you need any help? \\
2. & Mike: & Yes, actually. I want to say the USA is a country, but I feel it's wrong. \\
3. & Teacher: & North America? \\
4. & Mike: & Yes, North America. But Canada? \\
5. & Teacher: & Hmm... do you have a good idea? \\
6. & Mike: & Because Mexico is also a part of North America. \\
7. & Teacher: & Yes, that's true. The English speaking part of the US? No, of America? \\
8. & Mike: & But Canada is an English speaking part too. \\
9. & Teacher: & So, you just want to focus on the US. \\
10. & Mike: & Yes, because Canada, they still have the Queen Elisabeth. \\
11. & Teacher: & I don't think there are that many alternatives to the USA. \\
12. & Mike: & What about North America? \\
13. & Teacher: & North America is probably a good alternative. \\
14. & Mike: & Yes, OK. ((writing)) \\
\hline
\end{tabular}

By offering various alternatives (lines 3, 7, 9 and 11) the teacher assists Mike's reasoning (lines 4, 6, 8, and 10) and structures the process of their joint knowledge coconstruction. This helps Mike to choose the most suitable alternative (line 12) and form his understanding of the concept discussed. 
The teacher facilitates the development of Mike's understanding of the concept "North America" by identifying its criterion - the English language. In fact, Mike includes the following in his final draft:

"Unfortunately, for the British, the colonies started to protest against their control. The North Americans broke loose from Britain during the American War of Independence."

Mike incorporates the alternative discussed with the teacher. From the perspective of Galperin's phases, he transfers the co-constructed knowledge from communicated to dialogical thinking.

Time: $11: 28$

The students of the comparison class have written their second drafts and in extract $2 \mathrm{c}$ in Table 8 they are in the process of giving feedback on their final drafts, moving from the phase of communicated to dialogical thinking. We enter when the teacher asks Mike:

\section{Table 8. Extract 2c}

1. Teacher: Do you have any questions?

2. Mike: Yes, I have one. Here ((points at the assessment rubric)) you say I have to have five subthemes. I have counted and I have five. I have some grammar mistakes, but what about the grade?

3. Teacher: You see this is a preliminary grade. This is not the grade you are going to have.

4. Mike: I see. But I am unsure what are we-

5. Teacher: Can I just get your text?

6. Mike: You have to look here ((points on the PC screen)) because I have changed so much. I had more than 500 words so I had to stop.

7. Teacher: The idea now is that you have to add and you have to shorten up a bit.

8. Josh: So, if it is $50 \%$ on history and $50 \%$ on other things - is it too much history?

9. Teacher: Yes. Remember that history is just one of the subthemes. Then you also have the Internet, mass media and so on.

10. Josh: But history can also explain why the Internet is in English because of the US.

11. Teacher: You can connect it that way.

12. Mike: Yes, OK.

In the final phase of the writing process, the teacher directs students' attention to the requirements of the assignment (line 7) and prompts the learners how to achieve them (lines 9 and 11). In doing so, the teacher performs the controlling function by reminding the students about the essential feature of their final drafts (variety of subthemes) and how to shape their essays to match the requirements of the task. 


\subsection{Discussion}

The analyses performed in this study focused on examining teachers' guidance when facilitating students' writing with the feedback from EssayCritic (target class) and collaborating peers (comparison class) and the patterns in the teachers' assistance are presented in Table 9.

Table 9. Patterns of teachers' facilitating in the target and comparison classes

\begin{tabular}{|c|c|c|}
\hline $\begin{array}{l}\text { Galperin's } \\
\text { pedagogical } \\
\text { phases }\end{array}$ & Target class & Comparison class \\
\hline Orientation & $\begin{array}{l}\text { Extract 1a } \\
-\quad \text { Setting up the writing process } \\
\text { - Revealing the potential of } \\
\text { EssayCritic and integrating } \\
\text { EssayCritic in students' learning }\end{array}$ & $\begin{array}{l}\text { Extract } 2 \mathrm{a} \\
\text { - } \quad \text { Setting up the writing process } \\
\text { - } \quad \text { Explaining the requirements of the } \\
\text { essay and how to meet them }\end{array}$ \\
\hline $\begin{array}{l}\text { Communicated } \\
\text { thinking }\end{array}$ & $\begin{array}{l}\text { Extract } 1 b \\
\text { - Shaping the students" conceptual } \\
\text { understanding (concept "bilingual") } \\
\text { - Interaction with EssayCritic }\end{array}$ & $\begin{array}{l}\text { Extract } 2 b \\
\text { - Shaping the student's conceptual } \\
\text { understanding (concept "North } \\
\text { America") }\end{array}$ \\
\hline $\begin{array}{l}\text { Dialogical } \\
\text { thinking }\end{array}$ & $\begin{array}{l}\text { Extract 1c } \\
\text { - By interacting with EssayCritic, } \\
\text { initiating the learners' reflections on } \\
\text { the essential requirements of the } \\
\text { essays }\end{array}$ & $\begin{array}{l}\text { Extract } 2 c \\
\text { - Clarifying the essential requirements of } \\
\text { the essays and prompting the learners } \\
\text { on how to meet them }\end{array}$ \\
\hline
\end{tabular}

The analyses of teacher-students' interactions revealed the patterns in teachers' facilitating of the writing process in both classes. These patterns make visible that the teachers: i) set up the learning process in the orientation phase; ii) assisted the development of students' conceptual understanding in the phase of communicated thinking; and iii) brought learners' attention to the essential requirements of the essays in the phase of dialogical thinking. The quantitative data showed that the teachers provided more assistance in the phases of orientation and communicated thinking than in the dialogical thinking. This might potentially indicate that learners require more guidance at the beginning and the middle of the writing process rather than in its final phase. In fact, the ideas discussed with the teachers were incorporated in students' essays in both classes.

While these patterns of the teachers' interventions reflect in general the way practitioners might facilitate the writing process with and without technology (Del Rio \& 
Alvarez, 2007; Thompson, 2012), the analyses in the target class revealed the way the technology affected teacher's facilitating of students' writing which implied: i) introducing the technology to the learners, revealing its potential and integrating EssayCritic in students' learning in the orientation phase, ii) relying and interacting with EssayCritic when assisting the development of students' conceptual understanding in the phase of communicated thinking and iii) taking advantage of EssayCritic when initiating the learners' reflections about the essential requirements in the phase of dialogical thinking. Therefore, EssayCritic was present, constantly affected and supplemented the teacher's assistance in all the phases of the writing process. On the one hand, the feedback provided by EssayCritic coincided with the five key strategies of formative assessment (Black \& Wiliam, 2009): it clarified and shared learning intentions and criteria for success (feedback on covered and suggested subthemes); engineered effective classroom discussions (initiated group discussions to make sense of the feedback); provided feedback that moved learners forward (suggested subthemes); activated students as instructional resources for one another (initiated group discussions), and as owners of their own learning (individual feedback on multiple drafts). On the other hand, the teacher, as facilitator, integrated EssayCritic in students' learning and interacted with it when guiding students' writing. In fact, the quantitative analysis showed that the teacher in the target class provided significantly less guidance in the first two phases of the writing process than the teacher in the comparison class, which might indicate that the feedback given by EssayCritic might have occasionally substituted the teacher's assistance.

However, Galperin's types of orientation provide an insight into the conditions of mediation in both classes and suggest that the students in the target class were exposed to socalled complete orientation. In other words, the mediational means that encapsulated the essential requirements of the essays were readily available for the learners: individually tailored feedback on covered and suggested subthemes (EssayCritic), collaborating peers, teacher's interventions and the assessment rubric with the list of subthemes. The analyses revealed that the assessment rubric was hardly used by the students, which might suggest that the learners and the teacher relied extensively on the feedback from EssayCritic. The feedback in the form of covered and suggested subthemes, in turn, provided very specific instructions about how to solve a particular task: write an essay on the chosen topic with the requirement of a variety of subthemes. With this type of feedback, the students' own selfassessment was not strongly evident. Reflecting on the four levels of feedback (Hattie \& Timperley, 2007), EssayCritic provided only feedback about the task (covered and suggested subthemes), but not about the processing of the task. The analyses also revealed that 
EssayCritic affected the teacher's facilitating: the instructions given by the practitioner were focused on integrating EssayCritic, relying on it and interacting with the program over time, indicating an occurring dependency of the teacher on the technology. Such close interaction with EssayCritic and the specific cues given to the students by EssayCritic appeared to downplay an emphasis on the learners exercising their own AfL skills. By interacting closely with EssayCritic the teacher supported the frame of the complete orientation of the writing process and little attention was paid to the feedback about the processing of the task at what appeared to be the expense of the development of students' AfL skills and capacity to control the writing process.

In the comparison class the assessment rubric with the list of the subthemes, the students' essays, the peers and the teacher were the resources available. The learners' previous experience in the AfL practice served as a general approach the students were to pursue in using these mediational tools to assist them in writing essays matching the essential requirement: the variety of subthemes. This indicates that the students were exposed to Galperin's orientation of the third type: complete but created by learners following a general approach. The nature of the teacher's instructions was also different: the teacher emphasised the essential feature of the essays (variety of subthemes) for the learners in the orientation phase (extract 2a) which might have revealed the general AfL approach the learners were to pursue (feedback about the task and about processing of the task) (Hattie \& Timperley, 2007). In addition, the teacher brought the learners' attention to the requirement of the variety of subthemes in the dialogical thinking (extract 2c) which might have reminded the students about the AfL approach they could have followed when analysing and shaping their final drafts. In doing so, the teacher appeared to contribute to the development of students' understanding of the approach to the analysis and the essential requirements of the essays. Therefore, the teacher's actions might have contributed to the development of learners' AfL skills and enhancing of their agentic control over the writing process.

\subsection{Implications and directions for further research}

There are several implications for classroom pedagogy related to facilitating the writing process in ESL/EFL classes. First, the patterns in teachers' assistance reveal what teachers do when facilitating students' writing: set up the writing process in the orientation phase, assist the development of students' conceptual understanding in the phase of communicated thinking and encourage learners' reflections about the essential requirements 
of the final drafts in dialogical thinking. In other words, educationists' guidance fulfils the orienting, executive and control functions when facilitating the writing process.

The second implication is that technology may affect teachers' guidance of the learning process. In the target class, one outcome of the use of EssayCritic appeared to be a strong teacher reliance on its direct feedback. In doing so, the teacher did not encourage students to develop their own AfL skills and augment their own capacities for selfassessment. The study therefore raises questions about the need for practitioners' awareness of whether the technology supports the development of, for example, AfL skills required in ESL/EFL writing classes.

This concern also indicates the need for further modifications of EssayCritic to incorporate the requirements of Galperin's orientation of the third type (complete but created by learners following a general approach). Such a modification could assist students in recognising and articulating an approach they may pursue in the analysis of essays and in doing so, developing their understanding of what the essays are making and how well they are meeting them.

The third implication is that Galperin's pedagogical phases appeared to be helpful as a lens to understand the dialectics of writing process and as a tool to examine and conceptualise the nature of teachers' pedagogic interactions with groups of students at different phases in the writing process. Additionally, Galperin's types of orientation provided an explanation for the conditions of mediation in both classes. Such use of Galperin's conceptual contribution in empirical research might have implications for further studies that have learning and teaching process as a focal area.

However, the findings also showed that the sequential linearity of the transformation from the orientation to dialogical thinking, suggested originally by Galperin, was disrupted by the presence of EssayCritic in the writing process. The students and the teacher relied on the feedback from EssayCritic during both group discussions (communicated thinking) and individual work (dialogical thinking). There was constant move between communicated and dialogical thinking, which had not been captured in Galperin's work. The analysis therefore showed students' and teacher's moves in both directions: from dialogical to communicated thinking, when seeking clarifications from the rest of the group or the teacher; and returning to materialised action when calling on the feedback from EssayCritic. The recursive nature of participants' engagement with EssayCritic might have implications for the design of digital tools and teachers' facilitating of learning activities with technology. 
These findings, therefore, inform practitioners about the types of instructions teachers give when facilitating the writing process. They also emphasise the crucial importance of teachers' awareness about the type of support technology provides with the purpose of integrating of technology to enhance their pedagogy and student learning.

\section{References}

Atkinson, J. M., \& Heritage, J. (1999). Transcript Notation - Structures of Social Action: Studies in Conversation Analysis. Aphasiology, 13(4-5), 243-249. doi: http://dx.doi.org/10.1080/026870399402073

Bitchener, J., \& Knoch, U. (2008). The value of written corrective feedback for migrant and international students. Language Teaching Research, 12(3), 409-431.

Black, P., \& Wiliam, D. (2009). Developing the theory of formative assessment. Educational Assessment, Evaluation and Accountability (formerly: Journal of Personnel Evaluation in Education), 21(1), 5-31. doi:http://dx.doi.org/10.1007/s11092-008-9068-5

Brevik, L. M. (2017). Strategies and shoes: Can we ever have enough? Teaching and using reading comprehension strategies in general and vocational programmes. Scandinavian Journal of Educational Research 61(1): 76-94. doi:10.1080/00313831.2015.1075310

Brookhart, S. M., Moss, C. M. \& Long, B. A. (2010) Teacher inquiry into formative assessment practices in remedial reading classrooms. Assessment in Education: Principles, Policy \& Practice, 17(1), 41-58. doi:http://dx.doi.org/10.1080/09695940903565545

Burgess, R., \& Sørhus , T. B. (2009). Passage engelsk vg1 studieforberedende program. Cappelen Damm AS.

Chaiklin, S. (2003). The zone of proximal development in Vygotsky's analysis of learning and instruction. In A. Kozulin, B. Gindis, V. S. Ageyev \& S. M. Miller Vygotsky's educational theory in cultural context, 1, 39-64. doi: http://dx.doi.org/10.1017/cbo9780511840975.004

Chin, S. S.-F., \& Hortin, J. A. (1993). Teachers' perceptions of instructional technology and staff development. Journal of educational technology systems, 22(2), 83-98. doi:http://dx.doi.org/10.2190/xb76-wy26cv9q-h9al

Chung, G. K., \& O'Neil Jr, H. F. (1997). Methodological Approaches to Online Scoring of Essays. Retrieved from: http://eric.ed.gov/?id=ED418101

Cohen, L., Manion, L., \& Morrison, K. (2011). Research methods in education. Milton Park. Abingdon, Oxon,[England]: Routledge.

Collins, A. (2001). The role of computer technology in restructuring schools. DOCUMENT RESUME, 31. Retrieved from http://files.eric.ed.gov/fulltext/ED341383.pdf\#page=31

Creswell, J. W. (2012). Qualitative inquiry and research design: Choosing among five approaches. Sage.

Crossouard, B. (2009) A sociocultural reflection on formative assessment and collaborative challenges in the states of Jersey, Research Papers in Education, 24(1), 77-93. doi:http://dx.doi.org/10.1080/13669870801945909

Álvarez, P. R., \& Àlvarez, A. (2007). Inside and Outside the Zone of Proximal Development. An ecofunctional Reading of Vygotsky. In H. Daniels, M. Cole, \& JV Wertch. The Cambridge Companion to Vygotsky, 276-303. Cambridge University Press. doi:http://dx.doi.org/10.1017/ccol0521831040.012

Derry, S. J., Pea, R. D., Barron, B., Engle, R. A., Erickson, F., Goldman, R., . . . Sherin, M. G. (2010). Conducting video research in the learning sciences: Guidance on selection, analysis, technology, and ethics. The Journal of the Learning Sciences, 19(1), 3-53. doi:http://dx.doi.org/10.1080/10508400903452884

Dikli, S. (2006). An overview of automated scoring of essays. The Journal of Technology, Learning and Assessment, 5(1). Retrieved from: https://ejournals.bc.edu/ojs/index.php/jtla/article/view/1640 
Edwards, A. (2015). Designing tasks which engage learners with knowledge. In I. Thompson, Designing Tasks in Secondary Education: Enhancing Subject Understanding and Student Engagement, 13-27. Routledge.

Ellis, R., Sheen, Y., Murakami, M., \& Takashima, H. (2008). The effects of focused and unfocused written corrective feedback in an English as a foreign language context. System, 36(3), 353-371.

Fellbaum, C. (1998). WordNet: Wiley Online Library. Retrieved from: http://onlinelibrary.wiley.com/doi/10.1002/9781405198431.wbeal1285/abstract?userIsAuthenticated=fa 1 se $\&$ deniedAccessCustomisedMessage $=$

Ferris, D. R. (2006). Does error feedback help student writers? New evidence on the short-and long-term effects of written error correction. Feedback in second language writing: Contexts and issues, 81104.

Ferris, D. R. (2010). Second language writing research and written corrective feedback in SLA. Studies in Second Language Acquisition, 32(02), 181-201.

Field, A. (2013). Discovering statistics using IBM SPSS statistics. Sage.

Galperin, P. (1969). Stages in the development of mental acts. A handbook of contemporary soviet psychology, 249-273. New York: Basic Books.

Gamlem, S. M., \& Munthe, E. (2014). Mapping the quality of feedback to support students' learning in lower secondary classrooms. Cambridge Journal of Education, 44(1), 75-92. doi:http://dx.doi.org/10.1080/0305764x.2013.855171

Geertz, C. (1973). The interpretation of cultures: Selected essays (Vol. 5019): Basic Books. Retriewed from: http://web.mit.edu/allanmc/www/geertz.pdf

Hancock, V., \& Betts, F. (1994). From the Lagging to the Leading Edge. Educational Leadership, 51(7), $24-29$. Retrieved from: http://eric.ed.gov/?id=EJ508285

Haenen, J. (2001). Outlining the teaching-learning process: Piotr Gal'perin's contribution. Learning and Instruction, 11(2), 157-170. doi:http://dx.doi.org/10.1016/s0959-4752(00)00020-7

Hartwell, P. (1985). Grammar, grammars, and the teaching of grammar. College English, 47(2), 105-127.

Hattie, J., \& Timperley, H. (2007). The power of feedback. Review of Educational Research, 77(1), 81-112. doi:http://dx.doi.org/10.3102/003465430298487

Hyland, K. (1990). Providing productive feedback. ELT journal, 44(4), 279-285. doi:http://dx.doi.org/10.1093/elt/44.4.279

Johns, A. M. (1995). Genre and pedagogical purposes. Journal of second language writing, 4(2), 181-190.

Kukich, K. (2000). Beyond automated essay scoring. IEEE intelligent systems and their Applications, 15(5), 2227. Retrieved from: http://ieeexplore.ieee.org/stamp/stamp.jsp?tp=\&arnumber=889104

Lee, C., Cheung, W. K. W., Wong, K. C. K., \& Lee, F. S. L. (2013). Immediate web-based essay critiquing system feedback and teacher follow-up feedback on young second language learners' writings: an experimental study in a Hong Kong secondary school. Computer Assisted Language Learning, 26(1), 39-60. doi:http://dx.doi.org/10.1080/09588221.2011.630672

Lee, C., Wong, K. C., Cheung, W. K., \& Lee, F. S. (2009). Web-based essay critiquing system and EFL students' writing: A quantitative and qualitative investigation. Computer Assisted Language Learning, 22(1), 57 72. doi:http://dx.doi.org/10.1080/09588220802613807

Lee, I. (2007). Assessment for learning: Integrating assessment, teaching, and learning in the ESL/EFL writing classroom. Canadian Modern Language Review/La Revue canadienne des langues vivantes, 64(1), 199213. doi: http://dx.doi.org/10.3138/cmlr.64.1.199

Linell, P. (2009). Rethinking language, mind, and world dialogically: interactional and contextual theories of human sense-making. Information Age Publishing.

Lockhart, C., \& Ng, P. (1995). Analyzing talk in ESL peer response groups: Stances, functions, and content. Language learning, 45(4), 605-651. doi: http://dx.doi.org/10.1111/j.1467-1770.1995.tb00456.x

Mann, H. B., \& Whitney, D. R. (1947). On a test of whether one of two random variables is stochastically larger than the other. The annals of mathematical statistics(18), 50-60.

Murray, D. (1972). Teach writing as a process not product. The Leaflet, 71(3), 11-14. Retrieved from: http://www.larue.k12.ky.us/userfiles/1085/Teach\%20Reading\%20as\%20Process\%20Not\%20Product\% 20Article.pdf

Mørch, A., Cheung, W., Wong, K., Liu, J., Lee, C., Lam, M., \& Tang, J. (2005). Grounding Collaborative Knowledge Building in Semantics-Based Critiquing. In R. H. Lau, Q. Li, R. Cheung, \& W. Liu (Eds.), Advances in Web-Based Learning - ICWL 2005 (Vol. 3583, pp. 244-255): Springer Berlin Heidelberg. Retrieved from: https://telearn.archives-ouvertes.fr/hal-00190025

Rambusch, J. (2006). Situated learning and Galperin's notion of object-oriented activity. Paper presented at the The 28th Annual Conference of the Cognitive Science Society. Retrieved from: http://csjarchive.cogsci.rpi.edu/Proceedings/2006/docs/p1998.pdf 
Reid, J. (1994). Responding to ESL Students' Texts: The Myths of Appropriation. Tesol Quarterly, 28(2), 273292. doi: $10.2307 / 3587434$

Rindal, U. (2010). Constructing identity with L2: Pronunciation and attitudes among Norwegian learners of English. Journal of Sociolinguistics 14(2): 240-261.doi: 10.1111/j.1467-9841.2010.00442.x

Rindal, Ulrikke Elisabeth \& Piercy, Caroline (2013). Being 'neutral'? English pronunciation among Norwegian learners. World Englishes. ISSN 0883-2919. 32(2), s 211- 229 . doi: 10.1111/weng.12020

Quinlan, J. R. (1986). Induction of decision trees. Machine learning, 1(1), 81-106. doi: http://dx.doi.org/10.1007/bf00116251

Sheen, Y. (2007). The effect of focused written corrective feedback and language aptitude on ESL learners' acquisition of articles. Tesol Quarterly, 41(2), 255-283.

Sireci, S. G., \& Rizavi, S. (2000). Comparing Computerized and Human Scoring of Students' Essays. Retrieved from: http://files.eric.ed.gov/fulltext/ED463324.pdf

Smagorinsky, P. (2007). Teaching English by Design: How to Create and Carry Out Instructional Units. Heinemann. Retrieved from: http://eric.ed.gov/?id=ED498476

Smith, K., Gamlem, S. M., Sandal, A. K., Engelsen, K. S., \& Tong, K.-w. (2016). Educating for the future: A conceptual framework of responsive pedagogy. Cogent Education, 3(1), 1227021. doi:10.1080/2331186X.2016.1227021

Stetsenko, A., \& Arievitch, I. (2002). Teaching, learning, and development: A post-Vygotskian perspective. In G. Wells \& G. Claxton Learning for life in the 21st century: Sociocultural perspectives on the future of education, 84-96. John Wiley \& Sons. doi:http://dx.doi.org/10.1002/9780470753545.ch7

Thompson, I. (2012). Stimulating reluctant writers: a Vygotskian approach to teaching writing in secondary schools. English in Education, 46(1), 85-100. doi:http://dx.doi.org/10.1111/j.1754-8845.2011.01117.x

Thompson, I. (2013). The mediation of learning in the zone of proximal development through a co-constructed writing activity. Research in the Teaching of English, 47(3), 247-276. Retrieved from: http://www.ncte.org/library/nctefiles/resources/journals/rte/0473-feb2013/rte0473mediation.pdf

Truscott, J. (1996). The Case Against Grammar Correction in L2 Writing Classes. Language learning, 46(2), 327-369. doi:10.1111/j.1467-1770.1996.tb01238.x

Vygotsky, L. (1981). The genesis of higher mental functions. The concept of activity in Soviet psychology, 144188. New York: Sharpe.

Winerip, M. (2012). Facing a robo-grader? just keep obfuscating mellifluously. New York Times, 22. Retrieved from: http://thelawsofrobotics2013.iankerr.ca/files/2013/09/49-Facing-a-RoboGrader.pdf

Yang, M., Badger, R., \& Yu, Z. (2006). A comparative study of peer and teacher feedback in a Chinese EFL writing class. Journal of second language writing, 15(3), 179-200. doi:http://dx.doi.org/10.1016/j.jslw.2006.09.004

Zhao, H. (2010). Investigating learners' use and understanding of peer and teacher feedback on writing: A comparative study in a Chinese English writing classroom. Assessing Writing, 15(1), 3-17. doi: http://dx.doi.org/10.1016/j.asw.2010.01.002 